\title{
Aging of a copper bearing HSLA-100 steel
}

\author{
SANJAY PANWAR, D B GOEL*, O P PANDEY ${ }^{\dagger}$ and K SATYA PRASAD \\ Department of Metallurgical and Materials Engineering, Indian Institute of Technology, Roorkee 247 667, India \\ ${ }^{\dagger}$ School of Physics and Materials Science, Thapar Institute of Engineering and Technology, Patiala 147 004, India \\ ${ }^{\ddagger}$ Defence Metallurgical Research Laboratory, Hyderabad 500 058, India
}

MS received 6 June 2002; revised 1 April 2003

\begin{abstract}
Investigations were carried out on aging of a HSLA-100 steel after varying amounts of cold deformation. Mechanical properties (hardness, tensile properties and toughness) were measured and structural changes were studied using optical, TEM and SEM techniques. As a result of various treatments, the hardness and UTS could be significantly improved, but with drastic fall in ductility and impact strength, especially in peak aged conditions. The parameters affecting impact strength were examined and it was concluded that various microstructural features affected toughness through their influence on tensile properties. In this steel the impact strength could be improved by lowering the UTS and increasing the ductility (pct elongation). The improvement in hardness and UTS was attributed to formation of thick precipitate-dislocation tangles. The aging process caused a slow transformation of lath martensite into acicular ferrite due to occurrence of in situ recrystallization. The concentration of $\mathrm{Cu}$ in particles precipitating on aging was followed using EDAX technique.
\end{abstract}

Keywords. HSLA steel; thermomechanical aging; Cu-bearing steel.

\section{Introduction}

The Cu-containing age hardening steels have been of interest for a number of years owing to their desirable combination of strength and impact behaviour (Ranganathan 1999; Skoufari-Themistou et al 1999; Dhua et al 2001). The design philosophy underlying such steels is to reduce the carbon content to $\sim 0.05 \mathrm{wt}$ pct, to increase toughness and weldability and increase toughness via the precipitation hardening effects associated with high (1-2\%) $\mathrm{Cu}$ contents. In general, the precipitation strengthening effect of $\mathrm{Cu}$ is complimentary to the strengthening induced by other elements which are used for precipitation hardening, such as $\mathrm{Nb}, \mathrm{Ti}$ and $\mathrm{V}$; these being added to steels to control austenite grain size as well as subsequently to strengthen the transformed structure of ferrite, bainite or martensite. If a $\mathrm{Cu}$ bearing HSLA steel is given cold working treatment after austenitization, the dense dislocation-cluster network on aging should provide effective hindrance to the mobility of dislocations. At the same time, cold working should effectively induce aging of an austenitized HSLA steel when subjected to high temperature.

Resistance to brittle fracture has been a major concern in the development of HSLA steels. Studies on toughness of high strength steels have been attempted by various workers (Gordon et al 1993; Hamano 1993; Densley and

\footnotetext{
*Author for correspondence
}

Hirth 1998; Lee et al 1998). For development of high strength materials possessing reasonable toughness, it is important to understand the effect of precipitate phases on plastic deformation behaviour. For example, several age hardenable high strength materials show the lowest toughness and the maximum strength in the peak-aged condition (Higashi et al 1985). The coherent precipitates are easily cut by moving dislocations (Sanders and Starke 1982; Duerig et al 1985; Higashi et al 1985; Hamano 1993), which leads to inhomogeneous deformation, early crack initiation, and poor toughness. In the over aged condition, the strengthening precipitates are incoherent and can be bypassed by dislocations leading to homogeneous deformation and increasing toughness with delayed crack initiation. Accordingly, the high strength materials sometimes have to be used in the over aged condition with improved toughness, although at the cost of strength.

The present work was undertaken to study the aging behaviour of a Cu-bearing HSLA-100 steel and to identify microstructural effects on strengthening and impact strength of this steel.

\section{Experimental}

The steel with a composition (wt pct) C 0.04, Mn 0.86, P 0.004, S 0.002, Si 0.27, Cu 1.58, Ni 3.55, Cr 0.57, Mo 0.60 , Al 0.032 and $\mathrm{Nb} 0.03$ was provided by the Naval Research Laboratory, Washington in the form of plate of dimensions $300 \times 200 \times 50 \mathrm{~mm}$. The steel in the 
as-received (AR) condition possessed a mixed ferritebainite microstructure with fine carbonitride and $\mathrm{Cu}$ precipitates.

The steel in the AR condition was given the following treatments: (a) OQ: As-received material austenitized at $1000^{\circ} \mathrm{C}$ for $180 \mathrm{~min}$, followed by oil quenching; (b) QT: OQ treated material tempered at $450^{\circ} \mathrm{C}$ for $60 \mathrm{~min}$, followed by water quenching; (c) C25A: OQ treated material cold worked to 25 pct reduction by rolling followed by aging at $600^{\circ} \mathrm{C}$ for various times from $1 \mathrm{~min}$ to 1500 min, followed by water quenching; (d) C50A: OQ treated material cold worked to 50 pct reduction by rolling, followed by aging at $600^{\circ} \mathrm{C}$ for various times from $1 \mathrm{~min}$ to $1500 \mathrm{~min}$, followed by water quenching; (e) C80A: OQ treated material cold worked to 80 pct reduction by rolling, followed by aging at $600^{\circ} \mathrm{C}$ for various times from $1 \mathrm{~min}$ to $1500 \mathrm{~min}$, followed by water quenching and (f) TC25A: OQ treated material tempered at $700^{\circ} \mathrm{C}$ for $120 \mathrm{~min}$, followed by oil quenching, after which the material was cold worked to 25 pct reduction by rolling, followed by aging at $500^{\circ} \mathrm{C}$ for various times from $1 \mathrm{~min}$ to $3000 \mathrm{~min}$, followed by water quenching.

The treatments $\mathrm{C} 25 \mathrm{~A}, \mathrm{C} 50 \mathrm{~A}$ and $\mathrm{C} 80 \mathrm{~A}$ were given to produce particle-dislocation networks of different magnitudes. The TC25A treatment was carried out to make fine/coherent and coarse incoherent precipitates coexist in the matrix.

The Vickers hardness tests were performed to establish the aging curves. Cylindrical tensile specimens were prepared with a gauge length of $25 \mathrm{~mm}$ and a gauge diameter of $5 \mathrm{~mm}$. Tensile tests were conducted on Hounsfield tensometer with a crosshead speed of $1 \mathrm{~mm} / \mathrm{min}$. Charpy impact tests were performed at room temperature as per ASTM specifications. Extensive structural investigation was conducted using a high resolution light microscope, a $200 \mathrm{kV}$ transmission electron microscope and a $30 \mathrm{kV}$

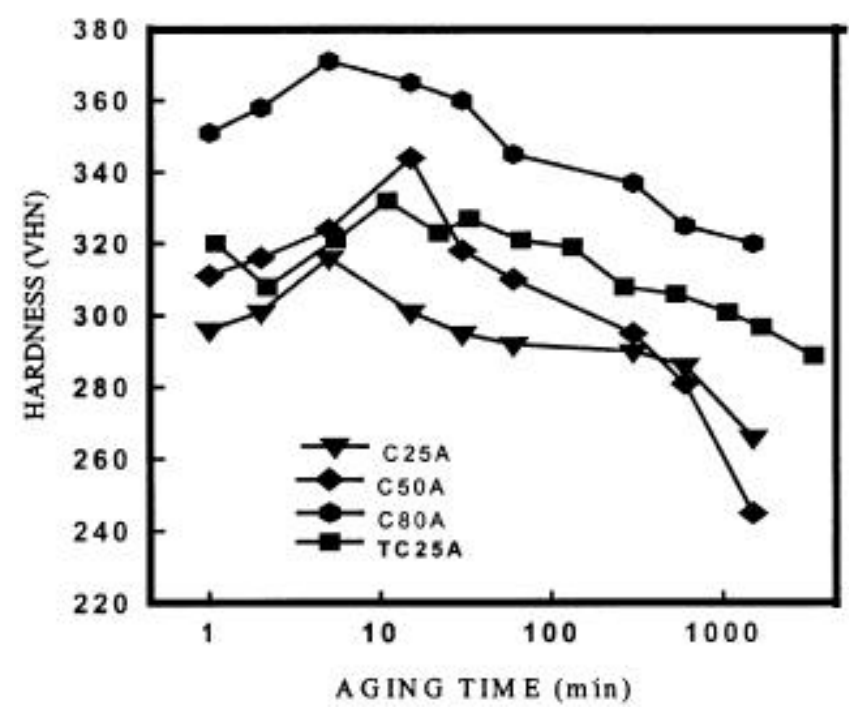

Figure 1. Variation of hardness with aging time. scanning electron microscope. Detailed examination and tests were conducted in cold worked (CW), peak aged (PA) and over aged (OA) conditions in the various treatments, as well as in the tempered (T) condition in TC25A treatment. In any treatment, OA condition refers to the end of aging process.

\section{Results}

\subsection{Mechanical properties}

The variation of hardness with aging time in the treatments of C25A, C50A, C80A and TC25A is given in figure 1. It was observed that maximum response to age hardening occurred in the $\mathrm{C} 80 \mathrm{~A}$ treatment, in which a hardness of $371 \mathrm{VHN}$ and UTS of $150 \cdot 34 \mathrm{~kg} \cdot \mathrm{mm}^{-2}$ could be obtained in PA condition. The peak occurred after 5 min of aging in $\mathrm{C} 25 \mathrm{~A}$ and $\mathrm{C} 80 \mathrm{~A}$ treatments, $15 \mathrm{~min}$ in C50A and $10 \mathrm{~min}$ in TC25A. Table 1 gives various mechanical properties obtained as a result of the treatments. It was observed that the high hardness and UTS in PA conditions compared to OA were generally accompanied by low ductility (pct elongation) and charpy impact strength, which may restrict the use of this steel. It may be noted that among all the treatments, the TC25A treatment in OA condition yields a high impact strength $\left(30 \cdot 30 \mathrm{~kg} \cdot \mathrm{m} \cdot \mathrm{cm}^{-2}\right)$, good hardness $(289 \mathrm{VHN})$ and UTS $\left(94.99 \mathrm{~kg} \cdot \mathrm{mm}^{-2}\right)$ together with reasonably good ductility (15.00 pct elongation), which is essential for practical applications.

\subsection{Optical metallography}

The structure in the as-quenched condition consisted of martensite laths together with some bright etching proeutectoid ferrite. Severe cold deformation by rolling caused shearing and fragmentation of laths of martensite. The laths tended to align along the flow lines developed due to cold rolling. Aging of cold deformed samples caused conversion of laths of martensite into acicular ferrite (figure 2). The examination at various stages of aging showed that the transformation of lath structure into acicular ferrite became slower as the amount of deformation prior to aging increased.

\subsection{Transmission electron microscopy (TEM)}

The TEM study of the oil quenched and cold worked specimens showed laths of high dislocation density. Severe cold working ( $80 \mathrm{pct}$ ) resulted in a much higher dislocation density as compared to 25 pct reduction. At 80 pct reduction thick tangles of dislocations were produced at lath boundaries as well as within the laths. The transmission electron micrographs of the specimens after 
Table 1. Mechanical properties of HSLA-100 steel.

\begin{tabular}{|c|c|c|c|c|c|}
\hline Treatment & Designation & $\begin{array}{l}\text { Hardness } \\
\text { (VHN) }\end{array}$ & $\begin{array}{c}\text { UTS } \\
\left(\mathrm{kg} \cdot \mathrm{mm}^{-2}\right)\end{array}$ & $\begin{array}{l}\text { Elongation } \\
\text { (pct.) }\end{array}$ & $\begin{array}{c}\text { Impact strength } \\
\left(\mathrm{kg} \cdot \mathrm{m} \cdot \mathrm{cm}^{-2}\right)\end{array}$ \\
\hline $\mathrm{AR}$ & & 231 & $73 \cdot 70$ & $27 \cdot 60$ & $33 \cdot 80$ \\
\hline OQ & & 289 & $94 \cdot 31$ & $15 \cdot 56$ & $23 \cdot 25$ \\
\hline QT & & 291 & $89 \cdot 30$ & $16 \cdot 70$ & $26 \cdot 90$ \\
\hline \multirow{3}{*}{$\mathrm{C} 25 \mathrm{~A}$} & $\mathrm{CW}$ & 292 & $102 \cdot 61$ & $12 \cdot 32$ & $15 \cdot 88$ \\
\hline & PA & 316 & $103 \cdot 77$ & $13 \cdot 67$ & $16 \cdot 64$ \\
\hline & OA (1500 min) & 266 & $98 \cdot 49$ & $18 \cdot 81$ & $25 \cdot 39$ \\
\hline \multirow{3}{*}{$\mathrm{C} 50 \mathrm{~A}$} & CW & 300 & $109 \cdot 83$ & $10 \cdot 51$ & $16 \cdot 91$ \\
\hline & PA & 344 & $112 \cdot 82$ & $14 \cdot 03$ & $12 \cdot 28$ \\
\hline & $\mathrm{OA}(1500 \mathrm{~min})$ & 245 & $60 \cdot 24$ & $20 \cdot 81$ & $33 \cdot 42$ \\
\hline \multirow{3}{*}{$\mathrm{C} 80 \mathrm{~A}$} & $\mathrm{CW}$ & 331 & $126 \cdot 97$ & $2 \cdot 84$ & $4 \cdot 44$ \\
\hline & PA & 371 & $150 \cdot 34$ & $6 \cdot 26$ & $9 \cdot 80$ \\
\hline & OA (1500 min) & 320 & $129 \cdot 58$ & $6 \cdot 36$ & $9 \cdot 95$ \\
\hline \multirow{4}{*}{$\mathrm{TC} 25 \mathrm{~A}$} & $\mathrm{~T}$ & 269 & $87 \cdot 07$ & $16 \cdot 22$ & $26 \cdot 67$ \\
\hline & $\mathrm{CW}$ & 324 & $103 \cdot 03$ & $12 \cdot 66$ & $18 \cdot 45$ \\
\hline & PA & 332 & $106 \cdot 12$ & $13 \cdot 95$ & $19 \cdot 17$ \\
\hline & OA (3000 min) & 289 & 94.99 & $15 \cdot 00$ & $30 \cdot 30$ \\
\hline
\end{tabular}

CW: Cold worked; PA: peak aged; OA: over aged; T: tempered.
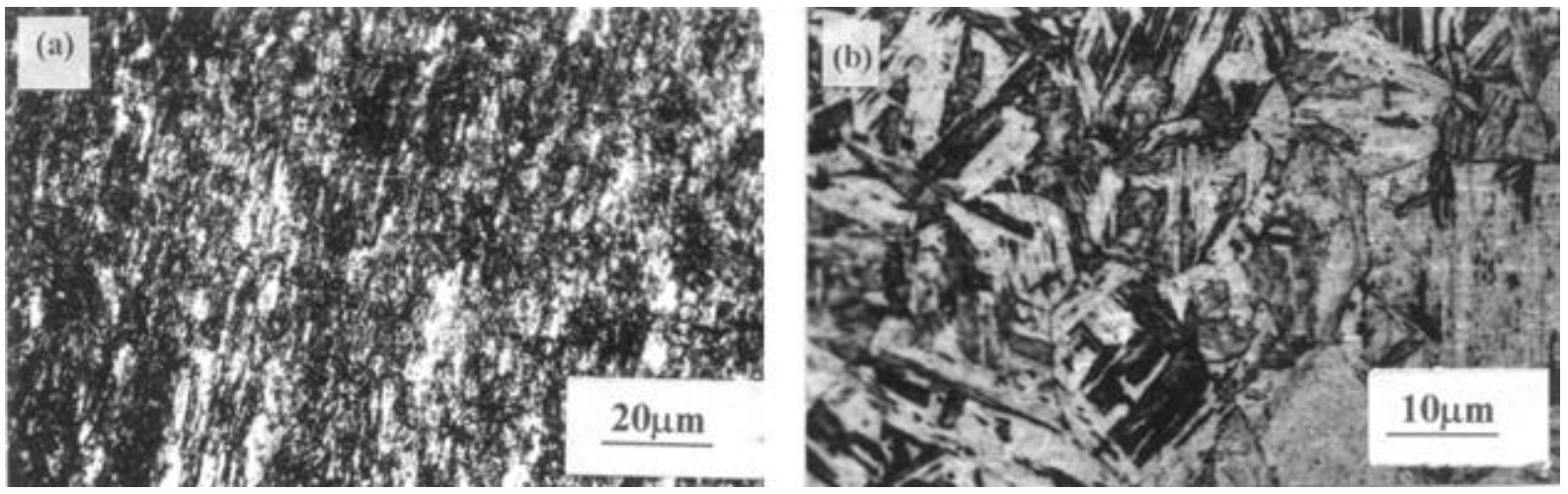

Figure 2. Microstructures after C80A treatment: (a) peak aged and (b) over aged.

various stages of aging are shown in figure 3. Coarse as well as fine precipitates were observed. The precipitates in case of high deformation (C80A) were, in general, more finely distributed. On the basis of $\mathrm{Cu}$ content, as determined from EDAX spectra, the precipitates were of two types: (i) having low $\mathrm{Cu}$ and (ii) high $\mathrm{Cu}$ content. At this stage of investigation it is not possible to say whether the two types of precipitates originated from the matrix differently, or the precipitates formed initially with low $\mathrm{Cu}$ content, which gradually increased as the particles grew in size. In pure $\mathrm{Fe}-\mathrm{Cu}$ alloys it has been reported (Goodman et al 1973; Leslie 1981) that, on aging low $\mathrm{Cu}$-bearing clusters are formed initially and as the particles grow, they become richer in $\mathrm{Cu}$. It has been reported by earlier workers (Leslie 1981) that the $\mathrm{Cu}$ content in these precipitates could vary from 50 to $100 \mathrm{wt}$ pct.

From figure 3 it is also seen that even in over aged condition $\left(600^{\circ} \mathrm{C}, 1500 \mathrm{~min}\right)$, the precipitate distribution was much finer in specimens cold worked to high deformations (C80A) as compared to $\mathrm{C} 25 \mathrm{~A}$. A dense dislocation substructure still existed in C80A. The TEM study also showed that aging of cold worked specimens was accompanied by subgrain growth leading to in situ recrystallization (figure 4). No significant formation and migration of high angle boundaries was observed. EDAX analysis showed that the subgrain growth process occurred by exodus of $\mathrm{Cu}$ atoms from some relatively unstable sub grains leading to their collapse.

\subsection{Scanning electron microscopy (SEM)}

The scanning electron micrographs of fracture surfaces of impact specimens in PA conditions are given in figure 5. In the case of TC25A and C25A treatments, which yielded high impact strength, the fracture surface showed 

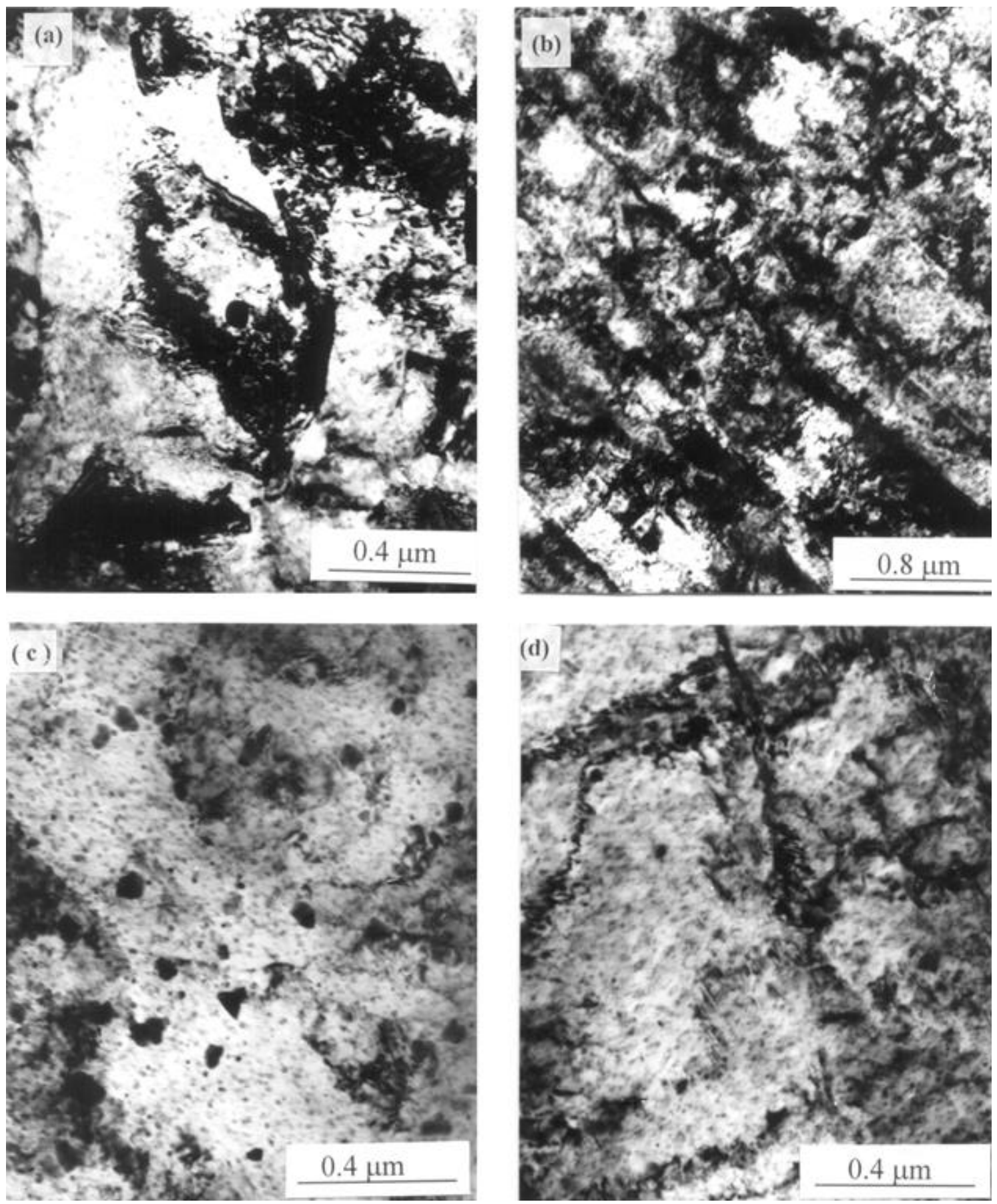

Figure 3. Transmission electron micrographs showing $\mathrm{Cu}$ precipitates: (a) peak aged, $\mathrm{C} 25 \mathrm{~A}$; (b) peak aged, C80A; (c) over aged, C25A and (d) over aged, C80A.

very fine distribution of micro dimples indicating a high resistance to cleavage fracture. It was observed that, in general, the fracture occurred by formation and coalescence of micro voids. The nucleation of microvoids was assisted by the presence of precipitate particles or inclusions as shown by arrows. In case of treatments involving high deformations (C50A and C80A), the fracture surface indicated quasi-cleavage appearance which is in confor- mity with low impact strength values observed in these cases.

\section{Discussion}

The cold working and aging treatments may cause precipitation of calcium oxysulfides, manganese sulfides and niobium carbides in addition to formation of $\mathrm{Cu}$-rich 
particles (Densley and Hirth 1998). Copper improves hardenability and introduces precipitation hardening. Although two precipitation hardening elements $(\mathrm{Cu}$ and $\mathrm{Nb}$ ) are present in this steel, the occurrence of single age

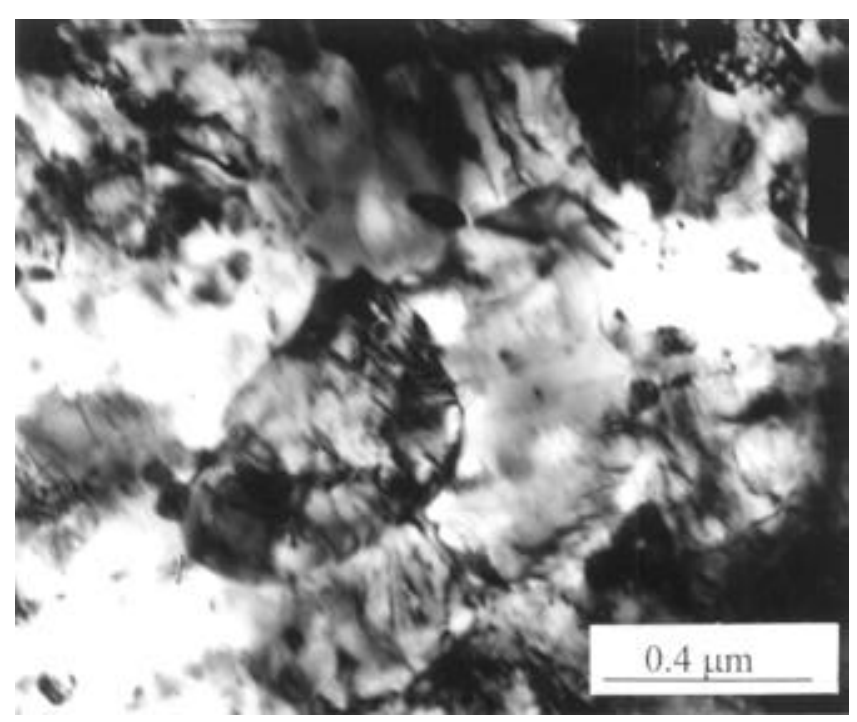

Figure 4. Transmission electron micrograph showing polygonization and in situ recrystallization (over aged, C80A). hardening peaks suggests that the precipitation hardening is primarily due to the presence of $\mathrm{Cu}$. Extensive TEM study was conducted to follow the precipitation of $\mathrm{Cu}$ bearing particles on aging/tempering of this steel. The study could not establish any relationship of coherent precipitates with the matrix. There is profuse precipitation of $\mathrm{Cu}$-bearing particles on aging/tempering and TEM is unable to detect any coherent particle with clarity. Although coherent and incoherent precipitation in $\mathrm{Cu}$-bearing HSLA steels was reported by some earlier researchers (Fox et al 1992; Mujahid et al 1998; Dhua et al 2001), they also could not provide sufficient TEM support for existence of coherent particles. Fox et al (1992) could not image $\mathrm{Cu}$ precipitates on tempering at $450^{\circ} \mathrm{C}$ and concluded that $\mathrm{Cu}$ precipitates must be of coherent type. Mujahid et al (1998) observed the presence of fine $\mathrm{Cu}$ clusters manifested by Moiré patterns. Dhua et al (2001) have reported formation of very fine $\mathrm{Cu}$-bearing precipitates of 10-15 $\mathrm{nm}$ size on quenching and on tempering at $400^{\circ} \mathrm{C}$. According to them these fine particles play the role of coherent particles in affecting the various mechanical properties.

The existence of a dislocation substructure in the presence of various alloying elements presents a very complex situation. As a result, it is observed that the formation
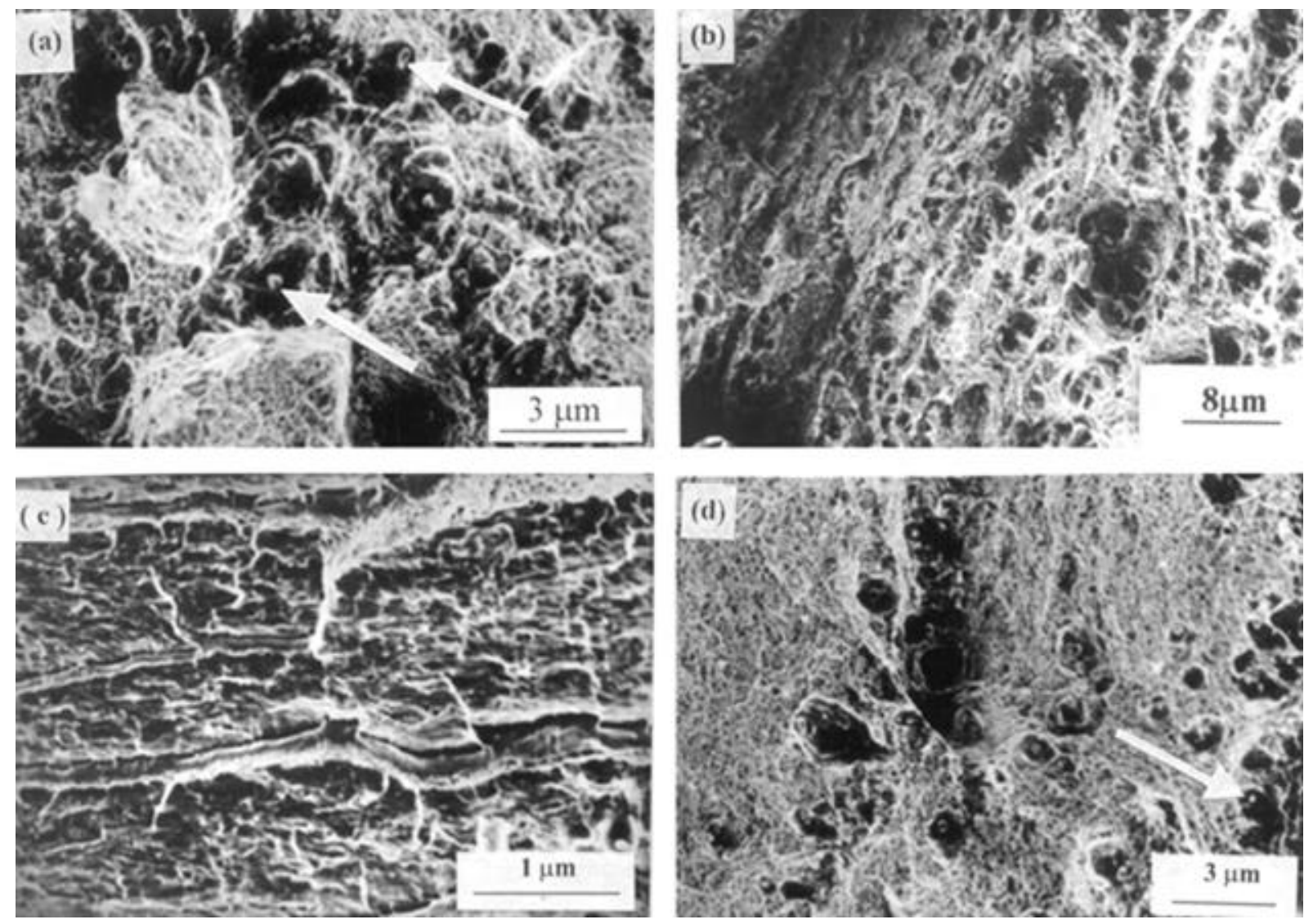

Figure 5. Scanning electron micrographs of impact fracture surface in peak aged conditions: (a) C25A, (b) C50A, (c) $\mathrm{C} 80 \mathrm{~A}$ and (d) TC25A. 
of age hardening peaks is not necessarily due to the existence of coherent $\mathrm{Cu}$ precipitates alone. The TEM study also shows (figure 3 ) that in peak aged specimens coarse $\mathrm{Cu}$ precipitates also exist in addition to fine precipitates. The dislocation networks introduced by cold working retard the transformation of martensite laths into ferrite. In C80A treatment a very slow transformation of lath structure into ferrite occurs due to high density of dislocations. With increasing deformations, the dislocationprecipitate tangles become highly immobile leading to conditions favourable for in situ recrystallization. As a result, high angle boundaries are formed only locally and annealing occurs without their large-scale movement. This process leads to formation of acicular ferrite from lath structure, especially in the case of C80A treatment. The low rate of phase transformation also helps in slowing down the over aging process significantly. In addition to $\mathrm{Cu}$ precipitates, the dissolved $\mathrm{Cu}$ atoms in the matrix also retard the polygonization and subgrain coalescence during aging in various treatments. As seen in this study, the subgrain growth occurs by migration of dissolved $\mathrm{Cu}$ solute atoms from relatively unstable subgrains towards more stable ones.

Cold working prior to aging of precipitation hardening alloys has many practical applications. In general, cold working of $\mathrm{Fe}-\mathrm{Cu}$ alloys and $\mathrm{Cu}$-containing steels enhances the practical applications. In general, cold working of $\mathrm{Fe}-\mathrm{Cu}$ alloys and $\mathrm{Cu}$-containing steels enhances the precipitation of $\mathrm{Cu}$; the time to reach peak hardness being reduced and higher hardness levels being achieved (Leslie 1981). At various degrees of cold working, the positions of hardening peaks may change due to competition between the recrystallization and aging processes. Accordingly, in this study, peak aging in C25A and C80A was observed after $5 \mathrm{~min}$, in C50A after $15 \mathrm{~min}$ and in TC25A after $10 \mathrm{~min}$.

Observation of low impact strength in peak aged conditions appears to be a matter of concern. The various treatments enhance the hardness and UTS, but significantly lower the impact strength in peak aged conditions. The C80A treatment, which results in the highest hardness and UTS, gives poorest charpy impact property. The TC25A treatment gives an optimum combination of tensile properties and impact strength. In the PA condition in all the treatments the charpy impact strength went down to very low values. The strengthened matrix is obviously detrimental for notch toughness. Mujahid et al (1998), Wilson et al (1988), Dhua et al (2001) and Hamano (1993) also observed similar dips in the CVN values in peak aged condition in their studies on HSLA steels. There have been various attempts to study the causes of poor impact strength in peak aged alloys (Sanders and Starke 1982; Duerig et al 1985; Higashi et al 1985). According to Hamano (1993) and Skoufari et al (1999), poor ductility and impact strength are due to existence of coherent precipitates in peak aged condition.
The coherent precipitates are easily cut by moving dislocations, which leads to concentration of slip in only a few slip bands. This localization of deformation causes an early initiation of cracks and poor toughness. On over aging the phenomenal improvement in toughness is due to the over aged microstructure of partially recovered matrix and coarse $\mathrm{Cu}$ precipitates, which might have helped in arresting the propagation of cleavage cracks. In the $\mathrm{C} 80 \mathrm{~A}$ treatment the coexistence of high dislocation density and fine/coherent $\mathrm{Cu}$ precipitates in the highly cold worked matrix causes rapid nucleation and growth of matrix cracks leading to very low CVN values. Even on over aging the recovery and recrystallization in the matrix are extremely slowed down due to dislocationprecipitate pinning. Thus in $\mathrm{C} 80 \mathrm{~A}$ the charpy impact value does not significantly improve even on over aging up to $1500 \mathrm{~min}$. The SEM study of impact fracture surfaces indicates that the fracture occurs by formation of microvoids at precipitate sites. The coherent/fine particles develop high stress concentrations at particle-matrix interfaces. These stresses, when combined with the stress fields of high density dislocation cells, cause localization of slip, nucleation of cracks and microvoids leading to poor impact strength. Accordingly, existence of coarse and incoherent precipitates causes an improvement in impact strength, as observed in over aged conditions.

All such microstructural features which trigger initiation of cracks and formation of microvoids, also affect the resultant tensile properties of the material. Miglin et al (1983) have attempted to correlate the effect of microstructural features on the impact strength through their effect on tensile properties. Figures 6(a) and (b) show respectively the relation between charpy impact strength with UTS and ductility. In these figures, data obtained from all the impact and tensile tests carried out at various stages of different treatments have been plotted. It is observed that the impact strength decreases with increase in UTS and increases with increase in ductility.

The influence of various mechanical properties on charpy impact strength is quite different in high strength precipitation hardenable materials. Since the hardness level in such materials is already quite high, any further
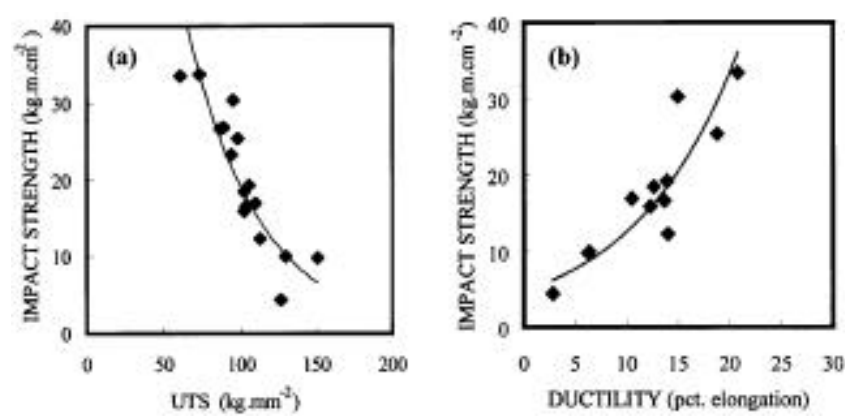

Figure 6. Variation of impact strength with (a) UTS and (b) ductility. 
increase in hardness results in embrittlement and poor impact strength. In general, the charpy impact strength in such cases is promoted by (i) ease of plastic flow, (ii) low response to work hardening and (iii) increasing ductility to avoid localized build up of stresses. Thus low UTS, which favours (i) and (ii), and high ductility should cause improvement in impact strength as is seen in figures 6 (a) and (b). It has been observed by Gladman et al (1976) in Nb-and V-bearing HSLA steels that the ductile to brittle transition temperature increases by 0.3 to $0.5^{\circ} \mathrm{C}$ for each $1 \mathrm{MPa}$ increase in yield strength. Miglin et al (1983) have shown in a HSLA steel that the $J_{1 \mathrm{C}}$ for ductile fracture decreases monotonically with increasing strength level. In a recent study (Sharma 1996) on high strength martensitic stainless steel, it has been observed that the erosion resistance, which improves with increasing toughness, is also improved by lowering of hardness and increase in ductility.

\section{Acknowledgement}

This investigation was supported under Indo-US Technical Cooperation Programme on 'Fundamental Studies on Advanced Ferrous Alloys'.

\section{References}

Densley J M and Hirth J P 1998 Scr. Metall. 39881
Dhua S K, Mukerjee D and Sarma D S 2001 Metall. Mater. Trans. A32 2259

Duerig T W, Allison J E and Williams J C 1985 Metall. Trans. A16 739

Fox A G, Mikalac S and Vassilaros M G 1992 Speich Symp. Proc. (Warrendale, PA: ISS) pp 1554-1561

Gladman T, Duilieu D and Mclvor I D 1976 Microalloying' 75 (Niagara Falls, NY: Union Carbide Corp.) p. 32

Goodman S R, Brenner S S and Low Jr S S 1973 Metall. Trans. A4 2363

Gordon J A, Hirth J P, Kumar A M and Moody Jr N E 1993 Metall. Trans. A23 1013

Hamano R 1993 Metall. Trans. A24 127

Higashi K, Hirari Y and Ohnishi T 1985 J. Jpn. Inst. Light Met. 35353

Lee S, Kim B C and Kwon D 1998 Metall. Trans. A24 1133

Leslie W C 1981 The physical metallurgy of steels (NY: McGraw Hill Book Co.) p. 133

Miglin M T, Hirth J P and Rosenfield A R 1983 Metall. Trans. A14 2055

Mujahid M, Lis A K, Garcia C I and DeArdo A J $1998 \mathrm{~J}$. Mater. Eng. Perf. 7247

Ranganathan S 1999 Mater. Sci. Technol. 15523

Sanders Jr T H and Starke Jr E A 1982 Acta Metall. 30927

Sharma M K 1996 Effect of welding parameters on the structure, properties and silt erosion in 13/4 martensitic stainless steel, $\mathrm{Ph}$ D Thesis, University of Roorkee, Roorkee

Skoufari-Themistou L, Crowther D N and Mintz B 1999 Mater. Sci. Technol. 151069

Wilson A D, Hamburg E G, Colvin D J, Thompson S W and Krauss G 1988 Proc. int. conf on microalloyed HSLA steels, Microalloying' 88 (Metals Park, OH: ASM International) pp 259-275 